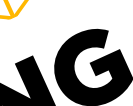

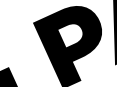

\section{wopk}

\section{Does Sibling Gender Affect Personality Traits?}

Bart H.H. Golsteyn

Cécile A.J . Magnée

Working Paper

2020-053

$07 / 2020$

HUMAN CAPITAL AND

ECONOMIC OPPORTUNITY

GLOBAL WORKING GROUP
The University of Chicago 1126 E. 59th Street Box 107 Chicago IL 60637 


\title{
Does Sibling Gender Affect Personality Traits?*
}

\author{
Bart H.H. Golsteyn ${ }^{* *}$, Cécile A.J. Magnée ${ }^{* * *}$
}

\begin{abstract}
This paper studies whether sibling gender affects personality traits. We use the idea that if parents decide to have a second child, it is random whether they will have a boy or a girl. Therefore, the relationship between the second-born sibling's gender and the first sibling's personality traits is causal. We employ longitudinal data from a large British cohort which is followed from birth onwards. The dataset includes personality traits at age 10 and 16. Our main result is that oldest boys in a household are more agreeable if their next-born sibling is a girl. This effect is robust across age (10 and 16), when controlling for among others family size, and when applying corrections for multiple hypothesis tests. Agreeableness is an important trait in life as it has been shown to correlate positively among others with being employed, having a skilled job, savings, and life satisfaction.
\end{abstract}

Keywords: sibling gender composition, personality traits

JEL: I2; J12, J16, J24

\footnotetext{
* This paper is forthcoming in the Economics of Education Review. The authors thank two anonymous referees, Chris van Klaveren, Arjan Non, Tyas Prevoo, Tom Stolp, Rolf van der Velden, Inge de Wolf and seminar participants at Maastricht University and Free University of Amsterdam for their valuable comments. This study was funded by the Netherlands Organization for Scientific Research (VIDI grant 452-16-006).

** Department of Economics, Maastricht University, P.O. Box 616, 6200 MD, Maastricht, the Netherlands. b.golsteyn@maastrichtuniversity.nl.

*** Corresponding author. CPB Netherlands Bureau for Economic Policy Analysis, P.O. Box 80510

2508 GM, The Hague, the Netherlands. c.a.j.magnee@cpb.nl.
} 


\section{Introduction}

The environment in which children grow up has vital implications for later in life outcomes. Parents, teachers, and peers determine choices children make. Interactions between siblings are also important. Studies have shown that the number of siblings, their birth order, and the age difference between siblings affect outcomes such as personality traits, human capital accumulation, and wages. ${ }^{1}$

Our paper investigates whether sibling gender affects personality traits. As proposed by Detlefsen et al. (2018), siblings may affect each other because they compete for parental attention or because they learn from each other. The effects are theoretically hard to predict as they may go in opposite directions. On the one hand, children may behave differently from their siblings in order to capture more parental attention (Sulloway, 1996; Hertwig et al., 2002). This is especially pronounced if siblings are of opposite gender (Feinberg et al., 2003). However, they may also show similar behavior as their sibling because they learn from each other. For example, Rust et al. (2000) shows that girls with brothers are more masculine and boys with sisters are more feminine.

We use the 1970 British Cohort Study, a longitudinal database consisting of approximately 18,000 children born in the UK in one week of April 1970, to study whether the gender of the second-born sibling influences personality traits of oldest children. The children have been followed in 12 surveys from birth (parental survey) up to an age of 50. The data contain information on personality traits of the children at age 10 and 16, reported by the child's mother.

One analytical complexity of studying the effect of sibling gender on personality traits is that the decision to have a second child may be driven by the gender of the first-born's child. Therefore, the effect of the first-born's gender on the outcome of the second-born child may be biased. The estimates of the second-born sibling on the oldest sibling, however, are less concerning because once parents decide to have another child, it is random whether they will have a boy or a girl. ${ }^{2}$ The relationship of this second-born boy or girl on the first child's outcomes is causal. Therefore, it has become standard in the recent literature to only focus on the effect of the second-born sibling on the oldest sibling (see Brenøe, 2018, and Peter et al., 2018). We follow this strategy and study the effect of the gender of the second-born sibling on personality traits of the oldest sibling in the household.

A second analytical issue is that when analyzing many hypotheses, one faces the risk that results are statistically significant by chance (i.e., a false positive or type I error). We, therefore, apply several corrections for multiple hypothesis testing.

Our main results are that the gender of the sibling has implications for personality traits. Boys with a younger sister are more agreeable. This effect remains robust across age, when adding controls, when correcting for potentially selective attrition, and when applying corrections for multiple hypothesis testing. The implications of having a sister may be long lasting as agreeableness is an important trait in life. It has been shown to correlate positively among others with being employed, having a skilled job, savings, and life satisfaction. Parents,

\footnotetext{
${ }^{1}$ See, e.g., Barclay, 2015; Bjerkedal, Kristensen, Skejeret, \& Brevik, 2007; Black, Devereux, \& Salvanes, 2007; Buckles \& Munnich, 2012; Golsteyn \& Magnée, 2017; Hotz \& Pantano, 2015; Kalmijn \& van de Werfhorst, 2016; Rohrer, Egloff, \& Schmuckle, 2015.

${ }^{2}$ Only from 1978 onwards, trustworthy ultrasound machines were available to determine the gender of a child during the pregnancy. Thus, parents deciding to terminate a pregnancy in 1970 could not have based the decision on the gender of the fetus. Furthermore, Wilcox et al. (1995) find no relation between time of intercourse with respect to ovulation and sex of the resulting child and Gray et al. (1998) find no relation between maternal hormones and sex of the child.
} 
teachers and policy makers may use this information to target the children in need for help in these domains.

In previous studies, boys and girls have been shown to display stereotypical behavior. These differences in behavior can stem from different parental treatment conditional on the gender of the child (McHale et al., 2003; Danielsbacka et al., 2011; Pollet et al., 2009), innate differences between boys and girls, and differences in the way siblings interact. The literature on such sibling influences has mostly focused on birth order, age differences, and the number of siblings (references are mentioned in footnote 1).

The effects of sibling gender have less often been studied and most previous research has focused on the effects of sibling gender on educational attainment or wages. With respect to the effects of sibling gender on educational attainment, Butcher \& Case (1994), for instance, show that women raised only with brothers receive on average significantly more education than women raised with sisters, controlling for household size. These results, however, could not be replicated by later studies. Kaestner (1997) finds that sibling sex composition had little effect on educational achievement. Hauser \& Kuo (1998) use the Occupational Changes in a Generation Survey, the Survey of Income and Program Participation, and the National Survey of Families and Households and find no relationship between the gender composition of sibships and women's educational attainment. Evidence of the effects of sibling sex composition on later in life outcomes has also been gathered in developing countries. Vogl (2013) examines how arranged marriage cultivates rivalry among sisters in South Asia. During marriage search, parents with multiple daughters rush older daughters' marriage to have sufficient time for her younger sisters to marry. Vice versa, older sisters delay the younger sister's marriage. As a consequence, younger sisters cause women to leave school earlier, to attain lower literacy levels, to find a husband with less education and a less-skilled occupation, and to attain a lower adult economic status.

Regarding the effects of sibling gender on wages, Brenøe (2018) finds that women with a brother acquire more traditional gender norms with negative consequences for their labor earnings. Rao \& Chatterjee (2018) show that the wages of men are increasing in the proportion of male siblings, while the wages of women are insensitive to sibling gender. Peter et al. (2018) find that a same-sex sibling increases men's earnings and family formation outcomes (marriage and fertility), as compared to an opposite-sex sibling. The results for women are similar but the effects are smaller in magnitude and less robust. Cools \& Patacchini (2019) show that women earn less when they have a younger brother relative to when they have a younger sister. Interestingly, these authors furthermore find that the lower earnings are partly driven by the fact that brothers reduce parents' expectations and school monitoring of female children while also increasing females' propensity to engage in more traditionally feminine tasks.

Our analysis contributes to this research by studying the effects of sibling gender on personality. There are few previous papers we know of which study closely related themes. One related analysis is a recent discussion paper by Detlefsen et al. (2018). They study the effects of birth order and sibling sex composition on economic preferences. They show, firstly, that second-born children are typically less patient, more willing to take risks, and more trusting. Secondly, second-born children are more willing to take risks if they have same-sex siblings than in a mixed-sex sibling case. For trust and trustworthiness, birth order effects are larger with mixed-sex siblings than in the single-sex case. Only for patience, siblings' sex composition does not matter.

A second related article studies the effects of sibling gender on cognitive and noncognitive skills. Cyron et al. (2017) find that boys benefit from having a sister in terms of cognitive skills, learning skills, and self-control measured in kindergarten. They also show that these effects have faded out by the time boys reach first grade. Girls' cognitive and non- 
cognitive skills are not affected by sibling gender. We contribute to this line of research by analyzing a greater variety of personality traits at ages 10 and 16 .

The paper proceeds as follows. Section 2 describes the data and Section 3 explains the methods. Section 4 reports the results, and checks the robustness of the findings. Section 5 concludes.

\section{Data}

We use data from the British Cohort Study (BCS70). This cohort study follows children who were born in the same week in April 1970 up until the age of 50. In total, 12 surveys have been conducted over this timespan. ${ }^{3}$ Table 1 gives summary statistics on the main variables for the full sample and for the sample used in our analyses.

\section{Siblings}

At age 5, mothers were asked to report the sex and birth date of children born after the child followed in the surveys. We use this information to define whether the child's next-born sibling is a boy or a girl and to determine the age gap between the first-born and second-born child. At age 10 , mothers were asked to list all members of the household. ${ }^{4}$ The data include the relationship to the child born in 1970 (e.g., brother, sister, father, etc.) and the sex of the person mentioned. We use these answers to elicit whether the child was the oldest child in the household and to determine the number of siblings in the household. Table 1 shows that the average household consisted of 2.2 children including the surveyed child itself.

\section{Personality traits}

The most used taxonomy of personality is the Big Five, consisting of openness to experiences, conscientiousness, extraversion, agreeableness, and neuroticism (positively framed as emotional stability) (Costa \& McCrae, 1992; Goldberg, 1993). During the childhood of the participating children, this taxonomy was not developed yet so standard items to measure these traits were not included. However, Prevoo and ter Weel (2015) show that the data contain items on personality and behavior at age 10 and 16 from which measures capturing a child's conscientiousness, extroversion, agreeableness, and emotional stability can be constructed. It is not possible to capture openness to experiences with the available items.

Table 2 shows the questions used to measure these traits. These questions were asked at age 10 and 16 to the child's mother and mostly refer to the child's behavior. In personality psychology it is common to measure personality constructs both by preferences and behavior. ${ }^{5}$

We first check whether the items indeed can be used to measure personality traits as suggested by Prevoo and ter Weel (2015). A rule of thumb is that items measure the same trait as long as the Eigenvalue in a factor analysis is above one for one factor only (see Kaiser, 1960). We find for each of the four clusters of items that the Eigenvalues of the first factor are indeed above unity and those of the second factor are below unity. However, the Eigenvalue of the first factor of extraversion is very close to unity. The table also shows the Cronbach's alphas associated to the traits. The personality psychology literature typically uses Cronbach's alphas as measures of reliability. Alphas of 0.7 or higher are considered reliable (see, e.g.,

\footnotetext{
${ }^{3}$ These surveys are held at the ages of 2, 5, 10, 16, 21, 26, 29, 34, 38, 42, 46 and 50 (in development).

${ }^{4}$ See page 2 at https://cls.ucl.ac.uk/wp-content/uploads/2017/07/parental.pdf. Since this information on family members is not available after age 10 of the child born in 1970, siblings who were born at a later time are not included in our analysis. This will not present any problems for our analysis since an age gap of more than 10 years implies that these siblings interact less intensively as they go through different life stages, and that age gaps of more than 10 years are not very common (see, e.g., Golsteyn \& Magnée 2017).

${ }^{5}$ For instance, the International Personality Item Pool website shows that conscientiousness is measured both by items that reveal preferences ("Like order") and also by items that ask about behavior ("Get chores done right away"). See: https://ipip.ori.org/newBigFive5broadKey.htm\#Conscientiousness.
} 
Kline, 2000). Using this benchmark, the traits appear to have high reliability at all ages, with the exception of extraversion at age 10 and 16. These findings confirm those by Prevoo and ter Weel (2015). Since the measure of extraversion is less reliable, we decided not to study the results for this trait in the remainder of this paper. The outcomes of this paper, therefore, include measures for conscientiousness, agreeableness and emotional stability.

In a second step, we elicit each trait by extracting the first principal component from the set of items belonging to that trait. As shown in Table 1, we then standardize these principle components to a mean of zero and a standard deviation of one based on the full sample. We do so in order to facilitate the interpretation of the size of the effects in our regression analyses. Comparing the number of observations on our personality trait variables in Table 1 also reveals the attrition in the data. At age 10, around 80 percent of the original sample of children is still in the sample. At age 16, around 62 percent is still in the sample. In the analyses, we will study whether attrition affects our results using inverse probability weighting.

\section{Controls}

In our regressions, we control for whether the mother was married at the time when the child was born. Table 1 shows that around 93 percent of the mothers were married at that time. In the regressions, we include a dummy variable for whether the mother was married.

We also control for the social class of the father and the mother of the children we follow. These are potentially important indicators of the environment in which the child is raised. Tables A1 and A2 display a list of occupations related to each social class. In our analyses, we include separate dummies for each social class.

The age difference between the surveyed child and its siblings may also affect our estimates, e.g. competition for parental attention may be larger when birth gaps are smaller. As mentioned above, at age 5, the data include information on the birth year of the sibling which was born after the surveyed child. If the first-born sibling after the surveyed child was born later than 5 years after the surveyed child, we set the age gap at 5 years.

\section{Estimation sample}

As we explain in the empirical strategy below, we study the effects only of the gender of the next-born sibling on the oldest child in the family. As a result, our estimation sample only includes children who were born in 1970 and who are the oldest child in households with at least two children. This implies that our sample reduces to 2,868 children. Roughly half of the sample is male. On average, the participant's family consists of 2.4 children including the child itself. The chance that the oldest child's next-born sibling is a brother is similar to the chance of having a sister. The age gap between the oldest child and its next-born sibling is around 34 months.

\section{Methodology}

The most important analytical complexity is that the decision to have a second child may be driven by the gender of the first-born's child. Therefore, the effect of the first-born's gender on the outcome of the second-born child may be biased. The estimates of the younger on the older siblings, however, are less concerning because once parents decide to have another child it is random whether they will have a boy or a girl. The relationship of this second-born boy or girl on the first child's outcomes is causal. Therefore, it has become standard in the recent literature to only focus on the effect of the younger on the older sibling (see Brenøe, 2018, and Peter et al., 2018). We follow this strategy and study the effect of the second-born sibling's gender on the oldest sibling's personality traits. We estimate the following type of regression models:

$$
\text { Personality }_{i}=\text { Sibling of Opposite Gender }{ }_{i} \delta+X_{i} \theta^{\prime}+\varepsilon_{i} \text {. }
$$


In these models, the vector of personality traits $P_{i}$ includes conscientiousness, agreeableness, and emotional stability of the oldest child in the household $i$. We run the regressions separately for boys and girls. Our baseline estimation uses personality traits measured at age 10. In order to capture the effect on personality traits of having a next-born sibling of the opposite gender relative to having a next-born sibling of the same gender, we include Sibling of Opposite Gender G $_{i}$ as our main independent variable. The effect of this variable is captured by the scalar $\delta$. The error term is denoted as $\varepsilon_{i}$.

In a second set of estimates, we additionally include $X_{i}$, a vector of control variables which includes whether the mother was married at the time when the child was born, the socioeconomic status of the father and the mother (dummy variables per category), and a continuous variable that measures the age gap between the child and its next-born sibling in months (with gaps larger than 5 years capped at 5 years).

In a third set of estimations, we check whether our results remain robust when we account for potentially selective sample attrition using inverse probability weights. We run auxiliary regressions of the probability to be in the sample on a set of variables including the sex of the participant (i.e. oldest child born in 1970), whether the mother is married and the social class of the father and mother. Using these estimates, we define the inverse probability weights which we include in the regressions.

In a final set of estimations, we check whether a type I error (i.e., a false positive) may occur because we test many hypotheses. We employ the most commonly used multiple hypothesis tests to account for such false positives. We test whether the results remain significant per set of six estimates, i.e. the effects on three personality traits for boys and three personality traits for girls at age 10 .

In sensitivity analyses, we analyze whether the estimates remain robust when including controls for the number of children in the household, and whether the estimates remain robust when using personality traits at age 16 .

\section{Results}

Table 3 shows the results of the effects of sibling gender on personality traits measured at age 10. Our first set of results shows that oldest girls are more agreeable at age 10 if they have younger brothers but when we control for other variables this effect is not robust.

We do find significant and robust effects of having a next-born sister on agreeableness of oldest boys in the household. Boys are 0.13 standard deviations more agreeable if they have a next-born sister relative to if they have a next-born brother. This effect remains robust when we include other variables in the regression and when we correct for multiple hypothesis testing. Table A3 in the Appendix shows that the results also remain robust when we include the number of children in the household as an additional control variable.

In Table 4 and A4, we investigate whether the results remain robust across age. The table reports the results of the effects of sibling gender on personality traits measured at age 16. Our main conclusion from this table is that also at age 16, boys are more agreeable if they have a next-born sister than if they have a next-born brother. The size of the effect increases to around 0.20 standard deviations more agreeableness if boys have a next-born sister.

\section{Conclusions}

This paper studies the effects of the gender of the sibling on personality traits. We employ a rich British data set, allowing us to follow children from birth until age 16. Our results show that boys are more agreeable if they have a next-born younger sister. Having a younger sister increases boys' agreeableness by around 0.13-0.20 standard deviations. We find this effect both at age 10 and at age 16 . 
We add to the existing literature by studying the effect of sibling gender on a broad range of personality traits at two ages. Cyron et al. (2017) only find positive effects on learning attitude and self-control of boys who have a sister at the start of kindergarten, but these effects have faded away by the time they reach first grade. In contrast, we find significant effects of sibling gender on personality traits at later ages, namely 10 and 16. Detlefsen et al. (2018) study effects of sibling gender on several economic preferences of 16 year old children, and find that second-born children are more willing to take risk if they have a same sex sibling, and boys show more trust and trustworthiness if they have a sister compared to girls who have a brother. They find no effects of sibling gender on patience. While they focus on economic preference parameters, we study effects of sibling gender on three of the Big Five traits, and find positive effects on agreeableness for boys if they have a next-born sister.

Personality traits correlate with important life outcomes. In Table A6 of their article, Prevoo and ter Weel (2015) show for instance that agreeableness correlates positively with being employed, having a skilled job, savings and life satisfaction, and that it correlates negatively with the likelihood to be a smoker at age 34 . Although we find that sibling gender affects agreeableness, we do not find significant relations between sibling gender and any of these life outcomes. This may be due to low statistical power or to other counteracting mechanisms through which sibling gender relates to these outcomes.

Parents and policy makers may use this information to target the children in need for help in these domains. A possibility for a policy intervention is to better inform teachers and parents about possible long-term risks. Future research could explore possible mechanisms, such as gender norms, to further explain the relationship between sibling gender and personality traits. 


\section{References}

Barclay, K. (2015). A within-family analysis of birth order and intelligence using population conscription data on Swedish men. Intelligence 49, 134-143.

Benjamini, Y., Hochberg, Y. (1995). Controlling the false discovery rate: a practical and powerful approach to multiple testing. Journal of the Royal Statistical Society. Series B (Methodological), 289-300.

Bjerkedal, T., Kristensen, P., Skejeret, G., Brevik, J. I. (2007). Intelligence test scores and birth order among young Norwegian men (conscripts) analyzed within and between families. Intelligence 35(6), 503-514.

Black, S., Devereux, P., Salvanes, K. (2007). Older and wiser? Birth order and IQ of young men. NBER working paper 13237.

Buckles, K., Munnich, E. (2012). Birth spacing and sibling outcomes. Journal of Human Resources 47(3), 613-642.

Brenøe, A. (2018). Origins of gender norms: sibling gender composition and women's choice of occupation and partner. IZA Discussion Papers No. 11692.

Butcher, K. Case, A. (1994). The effect of sibling sex composition on women's education and earnings. The Quarterly Journal of Economics 109(3), 531-563.

Cools, A., Patacchini, E. (2019). The Brother Earnings Penalty. Labour Economics 58, 37-51.

Costa, P. T., Jr., McCrae, R. R. (1992). Revised NEO Personality Inventory (NEO-PI-R) and NEO Five-Factor Inventory (NEO-FFI) professional manual. Odessa, FL: Psychological Assessment Resources.

Cyron, L., Schwerdt G., Viarengo, M. (2017). The effect of opposite sex siblings on cognitive and noncognitive skills in early childhood. Applied Economics Letters, 1-5.

Danielsbacka, M., Tanskanen, A.O., Jokela, M., Rotkirch, A. (2011). Grandparental child care in Europe: Evidence for preferential investment in more certain kin. Evolutionary Psychology 9(1), 3-24

Detlefsen, L., Lima de Miranda, K., Schmidt, U., Sutter, M. (2018). Are economic preferences shaped by the family context? The impact of birth order and siblings' sex composition on economic preferences. IZA Discussion Papers No. 11949.

Feinberg, M.E., McHale, S.M., Crouter, A.C., and Cumsille, P. 2003 Sibling Differentiation: Sibling and Parent Relationship Trajectories in Adolescence. Child Development, 74(5), 1261-1274.

Golsteyn, B., Magnée, C. (2017). Does birth spacing affect personality? Journal of Economic Psychology 60, 92-108.

Goldberg, L.R. (1993). The structure of phenotypic personality traits, American Psychologist $48,26-34$.

Gray, R. H., Simpson, J. L., Bitto, A. C., Queenan, J. T., Li, C., Kambic, R. T., ... Jennings, V. (1998). Sex ratio associated with timing of insemination and length of the follicular phase in planned and unplanned pregnancies during use of natural family planning. Human Reproduction (Oxford, England) 13(5), 1397-1400.

Hauser, R., Kuo, H. (1998). Does the gender composition of sibships affect women's educational attainment? The Journal of Human Resources 33(3), 644-657.

Hertwig, R., Davis, J. N., and Sulloway, F. J. 2002. Parental investment: how an equity motive can produce inequality. Psychological Bulletin, 128(5), 728-745.

Holland, B. S., Copenhaver, M. D. (1988). Improved Bonferroni-type multiple testing procedures. Psychological Bulletin 104(1), 145.

Holm, S. (1979). A simple sequentially rejective multiple test procedure. Scandinavian Journal of Statistics, 65-70. 
Hotz, V. J., Pantano, J. (2015). Strategic parenting, birth order, and school. Journal of Population Economics, 28(4), 911-936.Kanazawa, S. (2012). Intelligence, birth order and family size. Personality and Social Psychology Bulletin 38(9), 1157-1164.

Kaestner, R. (1997). Are brothers really better? Sibling sex composition and educational achievement revisited. The Journal of Human Resources 32(2), 250-284.

Kaiser, H. F. (1960). The application of electronic computers to factor analysis. Educational and Psychological Measurement 20, 141-151.

Kalmijn, M., van de Werfhorst, H. (2016). Sibship size and gendered resource dilution in different societal contexts, PLOS ONE 11(8), e0160953.

Kline, P. (2000). The handbook of psychological testing (2nd ed.). London: Routledge.

McHale, S.M., Crouter, A.C., Whiteman, S.D. (2003). The family contexts of gender development in childhood and adolescence. Social Development 12, 125-148.

Pollet, T.V., Fawcett, T.W., Buunk, A.P., Nettle, D. (2009). Sex-ratio biased towards daughters in among lower-ranking co-wives in Rwanda. Biology Letters 5(6), 765-768.

Prevoo, T., ter Weel, B. (2015). The importance of early conscientiousness for socio-economic outcomes: evidence from the British Cohort Study, Oxford Economic Papers 67(4), 918-948.

Rao, N., Chatterjee, T. (2018). Sibling gender and wage differences, Applied Economics 50(15), 1725-1745.

Rohrer, J. M., Egloff, B., Schmuckle, S. C. (2015). Examining the effects of birth order on personality. Proceedings of the National Academy of Sciences of the United States of America 112(46), 14224-14229.

Peter, N., Lundborg, P., Mikkelsen, S., Webbink, D. (2018). The effect of a sibling's gender on earnings and family formation. Labour Economics 54, 61-78.

Rust, J., Golombok, S., Hines, M., Johnston, K., Golding, J., and ALSPAC Study Team (2000). The role of brothers and sisters in the gender development of preschool children. Journal of Experimental Child Psychology, 77(4), 292-303.

Šidák, Z. (1968). On multivariate normal probabilities of rectangles: Their dependence on correlations. Annals of Mathematical Statistics 39, 1425-1434.

Simes, R. J. (1986). An improved Bonferroni procedure for multiple tests of significance. Biometrika 73(3), 751-754.

Sulloway, F. J. 1996. Born to rebel: Birth order, family dynamics, and creative lives. Pantheon Books.

Vogl, T. (2013). Marriage institutions and sibling competition evidence from South Asia. The Quarterly Journal of Economics 128(3), 1017-1072.

Wilcox, A. J., Weinberg, C. R., Baird, D. D. (1995). Timing of sexual intercourse in relation to ovulation - effects on the probability of conception, survival of the pregnancy, and sex of the baby. New England Journal of Medicine 333(23), 1517-1521. 
TABLES 
Table 1

Summary statistics

\begin{tabular}{lrrrrrr}
\hline & \multicolumn{3}{c}{ Full sample } & & Estimation sample \\
& $\mathrm{N}$ & Mean & St.Dev & $\mathrm{N}$ & Mean & St.Dev \\
\hline Conscientiousness age 10 & 13242 & 0 & 1 & 2782 & 0 & 1.002 \\
Agreeableness age 10 & 13153 & 0 & 1 & 2777 & .013 & .958 \\
Emotional stability age 10 & 13153 & 0 & 1 & 2768 & -.029 & .988 \\
Conscientiousness age 16 & 8461 & 0 & 1 & 1802 & .069 & .977 \\
Agreeableness age 16 & 8385 & 0 & 1 & 1790 & .008 & .982 \\
Emotional stability age 16 & 8345 & 0 & 1 & 1774 & -.015 & .987 \\
Survey child is male & 13869 & .516 & .5 & 2868 & .509 & .5 \\
Of oldest child in household, & 5095 & .524 & .499 & 2868 & .522 & .5 \\
next-born sibling is male & & & & & & \\
Number of children, incl. & 18751 & 2.181 & 1.197 & 2868 & 2.37 & .633 \\
survey child & & & & & & \\
Age gap between oldest and & 13058 & 49.648 & 14.955 & 2868 & 33.914 & 11.679 \\
second child (months) & & & & & & \\
Mother is married when child & 17179 & .926 & .261 & 2798 & .945 & .228 \\
is born & & & & & & \\
\hline
\end{tabular}

Note: The personality traits are standardized to a mean of zero and standard deviation of one based on the full sample. 
Table 2

Questions about personality traits answered by the mother at ages 10 and 16

\begin{tabular}{|c|c|c|c|c|}
\hline & Conscientiousness & Extraversion & Agreeableness & Emotional Stability \\
\hline Items & $\begin{array}{l}\text { cannot settle } \\
\text { easily distracted } \\
\text { fails to finish things } \\
\text { difficulty concentrating }\end{array}$ & $\begin{array}{l}\text { not much liked } \\
\text { worried } \\
\text { solitary } \\
\text { afraid of new } \\
\text { fussy/over-particular }\end{array}$ & $\begin{array}{l}\text { destroys belongings } \\
\text { fights with others } \\
\text { takes others' things } \\
\text { disobedient } \\
\text { tells lies } \\
\text { bullies others } \\
\text { interferes with others }\end{array}$ & $\begin{array}{l}\text { irritable } \\
\text { miserable/distressed } \\
\text { requests must be met } \\
\text { sullen or sulky } \\
\text { changes mood quickly } \\
\text { outbursts of temper }\end{array}$ \\
\hline Cronbach's alpha at age 10 & 0.82 & 0.58 & 0.81 & 0.82 \\
\hline Cronbach's alpha at age 16 & 0.81 & 0.57 & 0.78 & 0.84 \\
\hline
\end{tabular}

Notes: All personality items are answered by the child's mother. At age 10, the items are scored on a scale from 1 through 100,1 indicating 'certainly' and 100 indicating 'does not apply'. At age 16, the scoring is 1 'certainly applies,' 2 'applies somewhat,' 3 'doesn't apply' and for other traits 1 'not at all,' 2 'just a little,' 3 'pretty much,' and 4 'very much.' In the analyses, we recoded the items such that a high score implies respectively more conscientiousness, more agreeableness and more emotionally stability, and we standardize the traits to a mean of zero and a standard deviation of one. 
Table 3

Relationship between gender of the next-born sibling and personality traits of the oldest child at age 10

\begin{tabular}{|c|c|c|c|c|c|c|c|c|c|c|c|c|c|}
\hline & \multicolumn{4}{|c|}{ No controls } & \multicolumn{4}{|c|}{ With controls } & \multicolumn{4}{|c|}{ With controls and IPW } & $\begin{array}{c}\text { With controls and IPW } \\
\text { MHT }\end{array}$ \\
\hline \multicolumn{14}{|c|}{ Effects of next-born brother on female oldest sibling at age 10} \\
\hline & Coef & $\mathrm{Se}$ & $\mathrm{P}$ & $\mathrm{N}$ & Coef & $\mathrm{Se}$ & $\mathrm{P}$ & $\mathrm{N}$ & Coef & $\mathrm{Se}$ & $\mathrm{P}$ & $\mathrm{N}$ & \\
\hline Conscientiousness & -0.003 & 0.050 & 0.945 & 1372 & 0.015 & 0.052 & 0.778 & 1209 & 0.015 & 0.052 & 0.778 & 1209 & \\
\hline Agreeableness & 0.093 & 0.046 & 0.046 & 1375 & 0.045 & 0.047 & 0.337 & 1212 & 0.045 & 0.048 & 0.343 & 1212 & \\
\hline Emotional stability & 0.011 & 0.052 & 0.837 & 1362 & -0.011 & 0.054 & 0.837 & 1204 & -0.011 & 0.054 & 0.837 & 1204 & \\
\hline \multicolumn{14}{|c|}{ Effects of next-born sister on male oldest sibling at age 10} \\
\hline & Coef & $\mathrm{Se}$ & $\mathrm{P}$ & $\mathrm{N}$ & Coef & $\mathrm{Se}$ & $\mathrm{P}$ & $\mathrm{N}$ & Coef & $\mathrm{Se}$ & $\mathrm{P}$ & $\mathrm{N}$ & \\
\hline Conscientiousness & 0.022 & 0.056 & 0.700 & 1410 & 0.031 & 0.059 & 0.606 & 1274 & 0.031 & 0.059 & 0.606 & 1274 & \\
\hline Agreeableness & 0.131 & 0.055 & 0.018 & 1402 & 0.136 & 0.056 & 0.016 & 1265 & 0.136 & 0.057 & 0.017 & 1265 & All MHT: $\mathrm{p}<0.10$ \\
\hline Emotional stability & 0.034 & 0.054 & 0.535 & 1406 & 0.044 & 0.056 & 0.431 & 1271 & 0.044 & 0.056 & 0.431 & 1271 & \\
\hline
\end{tabular}

Note: Each coefficient represents a separate OLS regression. The table reports OLS regressions of having a next-born brother instead of a next-born sister for girls and having a next-born sister instead of a next-born brother for boys on various personality traits as dependent variables (displayed in the first column of the table). Standard errors, pvalues and the number of observations included in the regression are displayed next to each coefficient. All personality variables are standardized with mean zero and standard deviation of one based on the full sample. The first set of estimates only includes a dummy variable for the gender of the next-born sibling in the regression. The second set additionally includes controls for whether the mother was married at the time when the child was born, the socio-economic status of the father and the mother (dummy variables per category), and a continuous variable that measures the age gap between the child and its next-born sibling in months with birth gaps larger than 5 years set to 5 years. The third set is similar to the second set but additionally uses inverse probability weighting. The last set is similar to the third set but estimates whether the results hold when applying multiple hypothesis testing (MHT) corrections. We report at what level the results remain significant using the following tests: Bonferroni, Šidák (1968), Holm (1979), Holland \& Copenhaver (1988), Benjamini \& Hochberg (1995) and Simes (1986). 
Table 4

Relationship between gender of the next-born sibling and personality traits of the oldest child at age 16

\begin{tabular}{|c|c|c|c|c|c|c|c|c|c|c|c|c|c|}
\hline & \multicolumn{4}{|c|}{ No controls } & \multicolumn{4}{|c|}{ With controls } & \multicolumn{4}{|c|}{ With controls and IPW } & \multirow[t]{2}{*}{$\begin{array}{c}\text { With controls and IPW } \\
\text { MHT } \\
\end{array}$} \\
\hline \multicolumn{13}{|c|}{ Effects of next-born brother on female oldest sibling at age 16} & \\
\hline & Coef & $\mathrm{Se}$ & $\mathrm{P}$ & $\mathrm{N}$ & Coef & $\mathrm{Se}$ & $\mathrm{P}$ & $\mathrm{N}$ & Coef & $\mathrm{Se}$ & $\mathrm{P}$ & $\mathrm{N}$ & \\
\hline Conscientiousness & 0.057 & 0.059 & 0.328 & 954 & 0.075 & 0.061 & 0.221 & 845 & 0.074 & 0.063 & 0.237 & 845 & \\
\hline Agreeableness & 0.085 & 0.054 & 0.120 & 942 & 0.084 & 0.057 & 0.140 & 835 & 0.081 & 0.058 & 0.165 & 835 & \\
\hline Emotional stability & 0.057 & 0.066 & 0.385 & 938 & 0.096 & 0.068 & 0.161 & 832 & 0.093 & 0.069 & 0.183 & 832 & \\
\hline \multicolumn{14}{|c|}{ Effects of next-born sister on male oldest sibling at age 16} \\
\hline & Coef & $\mathrm{Se}$ & $\mathrm{P}$ & $\mathrm{N}$ & Coef & $\mathrm{Se}$ & $\mathrm{P}$ & $\mathrm{N}$ & Coef & $\mathrm{Se}$ & $\mathrm{P}$ & $\mathrm{N}$ & \\
\hline Conscientiousness & -0.110 & 0.071 & 0.124 & 848 & -0.069 & 0.074 & 0.351 & 774 & -0.067 & 0.075 & 0.366 & 774 & \\
\hline Agreeableness & 0.213 & 0.076 & 0.005 & 848 & 0.194 & 0.078 & 0.013 & 773 & 0.197 & 0.082 & 0.016 & 773 & All MHT: $\mathrm{p}<0.10$ \\
\hline Emotional stability & 0.114 & 0.067 & 0.088 & 836 & 0.113 & 0.069 & 0.101 & 762 & 0.116 & 0.070 & 0.098 & 762 & \\
\hline
\end{tabular}

Note: Each coefficient represents a separate OLS regression. The table reports OLS regressions of having a next-born brother instead of a next-born sister for girls and having a next-born sister instead of a next-born brother for boys on various personality traits as dependent variables (displayed in the first column of the table). Standard errors, pvalues and the number of observations included in the regression are displayed next to each coefficient. All personality variables are standardized with mean zero and standard deviation of one based on the full sample. The first set of estimates only includes a dummy variable for the gender of the next-born sibling in the regression. The second set additionally includes controls for whether the mother was married at the time when the child was born, the socio-economic status of the father and the mother (dummy variables per category), and a continuous variable that measures the age gap between the child and its next-born sibling in months with birth gaps larger than 5 years set to 5 years. The third set is similar to the second set but additionally uses inverse probability weighting. The last set is similar to the third set but estimates whether the results hold when applying multiple hypothesis testing (MHT) corrections. We report at what level the results remain significant using the following tests: Bonferroni, Šidák (1968), Holm (1979), Holland \& Copenhaver (1988), Benjamini \& Hochberg (1995) and Simes (1986). 


\section{APPENDIX}


Table A1 Socio-economic status father

\begin{tabular}{ll}
\hline Types of profession \\
\hline Social class I & $\begin{array}{l}\text { Professional occupations, including doctors, lawyers, } \\
\text { ministers of religion, university teachers, professional } \\
\text { engineers, etc. }\end{array}$ \\
Social class II & $\begin{array}{l}\text { Managerial and other processionals, including nurses, school } \\
\text { teachers, company directors, etc. }\end{array}$ \\
Social class III NM & $\begin{array}{l}\text { Non-manual skilled occupations, including ship assistants, } \\
\text { company representatives, clerical workers, draughtsman, etc. }\end{array}$ \\
Social class III M & $\begin{array}{l}\text { Skilled manual workers, including mechanics, craftsmen of all } \\
\text { types, skilled engineers, etc. }\end{array}$ \\
Social class IV & $\begin{array}{l}\text { Semi-skilled workers, including machine operators, postmen, } \\
\text { storekeepers, porters, caretakers, etc. }\end{array}$ \\
Social class $V$ & Unskilled workers, including laborers, cleaners, dustmen, etc. \\
Other &
\end{tabular}

Table A2 Socio-economic status mother

Social class I \& II

Types of profession

I: Professional occupations, including doctors, lawyers, ministers of religion, university teachers, professional engineers, etc.

II: Managerial and other processionals, including nurses, school teachers, company directors, etc.

Social class III NM

Non-manual skilled occupations, including ship assistants, company representatives, clerical workers, draughtsman, etc.

Social class III M

Skilled manual workers, including mechanics, craftsmen of all types, skilled engineers, etc.

Social class IV

Semi-skilled workers, including machine operators, postmen, storekeepers, porters, caretakers, etc.

Social class $V$

Unskilled workers, including laborers, cleaners, dustmen, etc.

Other

Housewives 
Table A3

Relationship between gender of the next-born sibling and personality traits of the oldest child at age 10, controlling for the number of children in the household

\begin{tabular}{|c|c|c|c|c|c|c|c|c|c|c|c|c|c|}
\hline & \multicolumn{4}{|c|}{ No controls } & \multicolumn{4}{|c|}{ With controls } & \multicolumn{4}{|c|}{ With controls and IPW } & $\begin{array}{c}\text { With controls and IPW } \\
\text { MHT }\end{array}$ \\
\hline \multicolumn{14}{|c|}{ Effects of next-born brother on female oldest sibling at age 10} \\
\hline & Coef & $\mathrm{Se}$ & $\mathrm{P}$ & $\mathrm{N}$ & Coef & $\mathrm{Se}$ & $\mathrm{P}$ & $\mathrm{N}$ & Coef & $\mathrm{Se}$ & $\mathrm{P}$ & $\mathrm{N}$ & \\
\hline Conscientiousness & -0.001 & 0.050 & 0.982 & 1372 & 0.023 & 0.052 & 0.661 & 1209 & 0.023 & 0.052 & 0.659 & 1209 & \\
\hline Agreeableness & 0.079 & 0.046 & 0.090 & 1375 & 0.038 & 0.047 & 0.422 & 1212 & 0.038 & 0.048 & 0.425 & 1212 & \\
\hline Emotional stability & 0.009 & 0.052 & 0.867 & 1362 & -0.006 & 0.054 & 0.911 & 1204 & -0.006 & 0.054 & 0.911 & 1204 & \\
\hline \multicolumn{14}{|c|}{ Effects of next-born sister on male oldest sibling at age 10} \\
\hline & Coef & $\mathrm{Se}$ & $\mathrm{P}$ & $\mathrm{N}$ & Coef & $\mathrm{Se}$ & $\mathrm{P}$ & $\mathrm{N}$ & Coef & $\mathrm{Se}$ & $\mathrm{P}$ & $\mathrm{N}$ & \\
\hline Conscientiousness & 0.017 & 0.057 & 0.759 & 1410 & 0.032 & 0.060 & 0.589 & 1274 & 0.032 & 0.06 & 0.591 & 1274 & \\
\hline Agreeableness & 0.099 & 0.055 & 0.070 & 1402 & 0.117 & 0.056 & 0.038 & 1265 & 0.117 & 0.056 & 0.038 & 1265 & \\
\hline Emotional stability & 0.007 & 0.054 & 0.899 & 1406 & 0.025 & 0.057 & 0.664 & 1271 & 0.025 & 0.057 & 0.665 & 1271 & \\
\hline
\end{tabular}

Note: Each coefficient represents a separate OLS regression. The table reports OLS regressions of having a next-born brother instead of a next-born sister for girls and having a next-born sister instead of a next-born brother for boys on various personality traits as dependent variables (displayed in the first column of the table). Standard errors, pvalues and the number of observations included in the regression are displayed next to each coefficient. All personality variables are standardized with mean zero and standard deviation of one based on the full sample. The first set of estimates includes a dummy variable for the gender of the next-born sibling in the regression and controls for the number of children in the household (dummies). The second set additionally includes controls for whether the mother was married at the time when the child was born, the socio-economic status of the father and the mother (dummy variables per category), and a continuous variable that measures the age gap between the child and its next-born sibling in months with birth gaps larger than 5 years set to 5 years. The third set is similar to the second set but additionally uses inverse probability weighting. The last set is similar to the third set but estimates whether the results hold when applying multiple hypothesis testing (MHT) corrections. We report at what level the results remain significant using the following tests: Bonferroni, Šidák (1968), Holm (1979), Holland \& Copenhaver (1988), Benjamini \& Hochberg (1995) and Simes (1986). 
Table A4

Relationship between gender of the next-born sibling and personality traits of the oldest child at age 16, controlling for the number of children in the household

\begin{tabular}{|c|c|c|c|c|c|c|c|c|c|c|c|c|c|}
\hline & \multicolumn{4}{|c|}{ No controls } & \multicolumn{4}{|c|}{ With controls } & \multicolumn{4}{|c|}{ With controls and IPW } & \multirow[t]{2}{*}{$\begin{array}{c}\text { With controls and IPW } \\
\text { MHT }\end{array}$} \\
\hline & Coef & $\mathrm{Se}$ & P & $N$ & Coef & $\mathrm{Se}$ & $P$ & $\mathrm{~N}$ & Coef & $\mathrm{Se}$ & P & $N$ & \\
\hline Conscientiousness & 0.052 & 0.059 & 0.379 & 954 & 0.068 & 0.061 & 0.265 & 845 & 0.067 & 0.062 & 0.280 & 845 & \\
\hline Agreeableness & 0.074 & 0.054 & 0.170 & 942 & 0.071 & 0.057 & 0.209 & 835 & 0.068 & 0.059 & 0.245 & 835 & \\
\hline Emotional stability & 0.055 & 0.066 & 0.405 & 938 & 0.098 & 0.068 & 0.152 & 832 & 0.095 & 0.069 & 0.169 & 832 & \\
\hline \multicolumn{14}{|c|}{ Effects of next-born sister on male oldest sibling at age 16} \\
\hline & Coef & $\mathrm{Se}$ & $\mathrm{P}$ & $\mathrm{N}$ & Coef & $\mathrm{Se}$ & $\mathrm{P}$ & $\mathrm{N}$ & Coef & $\mathrm{Se}$ & $\mathrm{P}$ & $\mathrm{N}$ & \\
\hline Conscientiousness & -0.114 & 0.072 & 0.114 & 848 & -0.063 & 0.075 & 0.399 & 774 & -0.061 & 0.075 & 0.415 & 774 & \\
\hline Agreeableness & 0.193 & 0.077 & 0.012 & 848 & 0.191 & 0.079 & 0.015 & 773 & 0.195 & 0.080 & 0.016 & 773 & All MHT: $\mathrm{p}<0.10$ \\
\hline Emotional stability & 0.112 & 0.067 & 0.098 & 836 & 0.125 & 0.070 & 0.074 & 762 & 0.128 & 0.070 & 0.069 & 762 & \\
\hline
\end{tabular}

Note: Each coefficient represents a separate OLS regression. The table reports OLS regressions of having a next-born brother instead of a next-born sister for girls and having a next-born sister instead of a next-born brother for boys on various personality traits as dependent variables (displayed in the first column of the table). Standard errors, pvalues and the number of observations included in the regression are displayed next to each coefficient. All personality variables are standardized with mean zero and standard deviation of one based on the full sample. The first set of estimates includes a dummy variable for the gender of the next-born sibling in the regression and controls for the number of children in the household (dummies). The second set additionally includes controls for whether the mother was married at the time when the child was born, the socio-economic status of the father and the mother (dummy variables per category), and a continuous variable that measures the age gap between the child and its next-born sibling in months with birth gaps larger than 5 years set to 5 years. The third set is similar to the second set but additionally uses inverse probability weighting. The last set is similar to the third set but estimates whether the results hold when applying multiple hypothesis testing (MHT) corrections. We report at what level the results remain significant using the following tests: Bonferroni, Šidák (1968), Holm (1979), Holland \& Copenhaver (1988), Benjamini \& Hochberg (1995) and Simes (1986). 